\title{
Recommendations for collaborative paediatric research including biobanking in Europe: a Single Hub and Access point for paediatric Rheumatology in Europe (SHARE) initiative
}

\author{
Jasmin B Kuemmerle-Deschner, ${ }_{1}^{1}$ Sandra Hansmann, ${ }^{1}$ Nico M Wulffraat, ${ }^{2}$ \\ Sebastiaan J Vastert, ${ }^{3}$ Kristien Hens, ${ }_{1}^{4}$ Jordi Anton, ${ }^{5}$ Tadej Avcin, ${ }^{6}$ Alberto Martini, ${ }^{7}$ \\ Isabelle Koné-Paut, ${ }^{8}$ Yosef Uziel, ${ }^{9,10}$ Angelo Ravelli, ${ }^{7}$ Carine Wouters, ${ }^{11}$ David Shaw, ${ }^{12,13}$ \\ Seza Özen, ${ }^{14}$ Andreas Eikelberg, ${ }^{1}$ Berent J Prakken, ${ }^{15}$ Nicolino Ruperto, ${ }^{7}$ \\ Gerd Horneff, ${ }^{16}$ Tamas Constantin, ${ }^{17}$ Michael W Beresford, ${ }^{18}$ Marijn Sikken, ${ }^{19}$ \\ Helen E Foster, ${ }^{20}$ Iris Haug, $_{1}$ Sabrina Schuller, ${ }^{1}$ Christine Jägle, ${ }^{1}$ Susanne M Benseler ${ }^{1,21}$
}

Handling editor Tore K Kvien

- Additional material is published online only. To view please visit the journal online (http://dx.doi.org/10.1136/ annrheumdis-2017-211904).

For numbered affiliations see end of article.

\section{Correspondence to} Susanne M Benseler, Rheumatology, Department of Pediatrics, Alberta Children's Hospital, University of Calgary, Calgary, AB T3B6A8, Canada; Susanne.Benseler@albert ahealthservices.ca

JBK-D and SH contributed equally.

Received 7 June 2017 Revised 19 August 2017 Accepted 8 September 2017

CrossMark

\section{To cite: Kuemmerle-} Deschner JB, Hansmann $\mathrm{S}$, Wulffraat NM, et al. Ann Rheum Dis Published Online First: [please include Day Month Year]. doi:10.1136/ annrheumdis-2017-211904

\section{ABSTRACT}

Innovative research in childhood rheumatic diseases mandates international collaborations. However, researchers struggle with significant regulatory heterogeneity; an enabling European Union (EU)-wide framework is missing. The aims of the study were to systematically review the evidence for best practice and to establish recommendations for collaborative research. The Paediatric Rheumatology European Single Hub and Access point for paediatric Rheumatology in Europe (SHARE) project enabled a scoping review and expert discussion, which then informed the systematic literature review. Published evidence was synthesised; recommendations were drafted. An iterative review process and consultations with Ethics Committees and European experts for ethical and legal aspects of paediatric research refined the recommendations. SHARE experts and patient representatives vetted the proposed recommendations at a consensus meeting using Nominal Group Technique. Agreement of $80 \%$ was mandatory for inclusion. The systematic literature review returned 1319 records. A total of 223 full-text publications plus 22 international normative documents were reviewed; 85 publications and 16 normative documents were included. A total of 21 recommendations were established including general principles (1-3), ethics (4-7), paediatric principles (8 and 9), consent to paediatric research (10-14), paediatric databank and biobank (15 and 16), sharing of data and samples (17-19), and commercialisation and third parties (20 and 21). The refined recommendations resulted in an agreement of $>80 \%$ for all recommendations. The SHARE initiative established the first recommendations for Paediatric Rheumatology collaborative research across borders in Europe. These provide strong support for an urgently needed European framework and evidence-based guidance for its implementation. Such changes will promote research in children with rheumatic diseases.

\section{INTRODUCTION}

Paediatric rheumatic diseases are rare and often devastating; advancing knowledge and improving care and outcomes of affected children mandates research collaborations across national borders. ${ }^{1-3}$ Across Europe, several national innovative research teams have made substantial contributions to developing clinical tools, biomarkers and imaging strategies for children with rheumatic diseases. Their evaluation and implementation mandates international patient cohorts and research partnerships given that some paediatric rheumatic diseases have incidences as low as one per million.

The European community strongly encourages collaborative international research and funded the 'Single Hub and Access point for paediatric Rheumatology in Europe (SHARE)' initiative, which aims to optimise care and research for children with rheumatic diseases across Europe. ${ }^{4-8}$ A key task was the identification of barriers between nations for collaborative Paediatric Rheumatology research. Currently, researchers funded to conduct important studies struggle with the substantial heterogeneity within and across European countries in all areas of rare diseases research. These include ethics approval process, consent and assent, formal frameworks for data and sample collection and sharing, and aspects of third party data and sample access. Currently, there is no EU-wide framework facilitating the conduct of collaborative rare diseases research. ${ }^{9}$

Therefore, the aims of the study were to synthesise the evidence for best practice in paediatric rheumatic diseases research and to develop recommendations to enable research collaborations including data- and biobanking across Europe.

\section{METHODS}

\section{Scoping review and expert consultation}

A scoping review on collaborative paediatric research was conducted identifying key themes. In addition, major stakeholders including ethics committee members, European Paediatric Rheumatology researchers and patients with rare diseases were asked to provide input regarding their perspectives on research and its barriers and challenges using structured interviews by surveys, phone and in-person. The group identified key themes and constructed an evaluative framework including a 


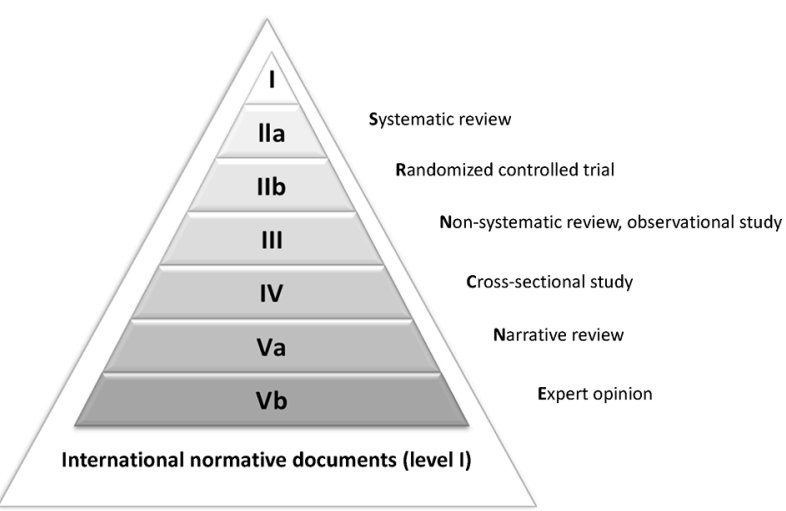

Figure 1 Modified hierarchy of evidence pyramid for inclusion of normative documents. The pyramid depicting the hierarchy of evidence was modified with guidance of the Cochrane collaboration to enable the inclusion of all available scientific evidence and international normative documents in the systematic review.

modification of the evidence ranking system supported by the Cochrane group (figure 1).

\section{Systematic review}

Search strategy and selection criteria

A systematic literature review anchored in the identified key themes was performed and reported according to the standards of the 'Preferred reporting items for systematic review and meta-analysis protocols (PRISMA)' guidelines. ${ }^{10} 11$ This systematic search of the literature aimed to identify studies of all aspects of paediatric research in Europe. These were specified in MESH terms and subheadings including data collection, ethics, biological specimen banks, confidentiality, informed consent by minors, specimen handling, jurisprudence, quality improvement, legislation, classification, methods, organisation, administration, standards and instrumentation. The search was performed in the electronic databases PubMed and Web of Science on 14 May 2014. The search was limited to articles published in English and children and adolescents (ages 0-18 years); the search period was set between January 1989 and April 2014, guided by the publication date of the United Nation's Convention on the Rights of the Child. ${ }^{12}$ In addition to the electronic literature search, a manual review of the references of all relevant publications and international and European normative documents was conducted. Articles were excluded, if the content was not related to children and adolescents, it did not apply to the European context or to any aspect of collaborative paediatric research.

\section{Data extraction and validity assessment}

The remaining full-text articles were reviewed by a panel of experts, graded by two independent researchers and reconciled by a third using predefined scoring instruments for the different study and publication types as appropriate..$^{13} 14$ The following variables were abstracted: reference, year of publication, authors, country of focus and contribution to the themes. Levels of evidence and strength of recommendations were determined using an adjusted framework for grading scientific evidence in order to account for normative documents including declarations, regulations, guidelines and legislative documents. ${ }^{15}$

\section{Development and refinement of recommendations}

Grouped by distinct themes, the evidence was synthesised; additional domains were developed including public opinion on paediatric research, guidelines and jurisdiction. Recommendations were drafted. In-depth discussion, iterative reviews and adjustments of the recommendations were completed with ethics committee staff members and international content experts in paediatric ethics $(\mathrm{KH})$ and legislation (DS). The draft version of the recommendations was sent to all SHARE experts in an online survey format for review and revision. All suggestions were integrated and additional recommendations were drafted; the revised documents were re-distributed to the experts for review and evaluation of agreement.

\section{Consensus meeting}

The proposed and reviewed recommendations were presented to the SHARE expert committee and patient representatives during a face-to-face consensus meeting in Rome, Italy, and discussed in-depth using Nominal Group Technique. ${ }^{16}$ Recommendations were accepted by reaching agreement above $80 \%$.

\section{RESULTS}

\section{Scoping review and expert consultation}

The key themes of collaborative paediatric research and biobanking in Paediatric Rheumatology were identified. These included ethics, legislation, consent, scope of consent, confidentiality, anonymisation, sample and data collection, handling and storage. These were translated into search terms to inform the evidence synthesis.

\section{Systematic literature review}

The initial search returned 7347 records, of which 6503 had to be excluded. Ultimately, 1319 publications including 844 from PubMed and 475 papers from the Web of Science Core Collection were identified. After removing 31 duplicates, a total of 1288 records were manually reviewed for title and abstract excluding 1065. Full-text assessment of 223 papers resulted in exclusion of 161. A total of 62 publications plus an additional 23 identified by targeted handsearch from references resulted in 85 papers to be included (see online supplementary table S1). A full-text review of 22 normative documents yielded 16 relevant documents including three international declarations, five guidelines, four European legislative documents and four recommendations (see online supplementary table S2 and figure 2 and box).

\section{Data extraction and validity assessment}

Among the 85 retained publications three publications were systematic reviews, defined as evidence level II a (none were II b), 15 were non-systematic reviews (evidence level III), 24 cross-sectional studies (level IV b), 16 narrative reviews and 27 expert opinions (evidence level V b). All 16 normative documents were found to be evidence level I.

\section{Development and refinement of recommendations}

Evidence was translated into draft recommendations. Themes identified were the following: guiding principles, ethics, paediatric principles, consent to paediatric research, paediatric data- and biobanks: operational principles, sharing of data and samples, commercialisation and third party access. In an iterative process, draft recommendations were reviewed and refined by consulting experts and the European SHARE panel.

\section{Consensus meeting}

A total of 21 recommendations were drafted, grouped into the domains of guiding principles (recommendation 1-3), ethics (recommendations 4-7), paediatric principles (recommendations 


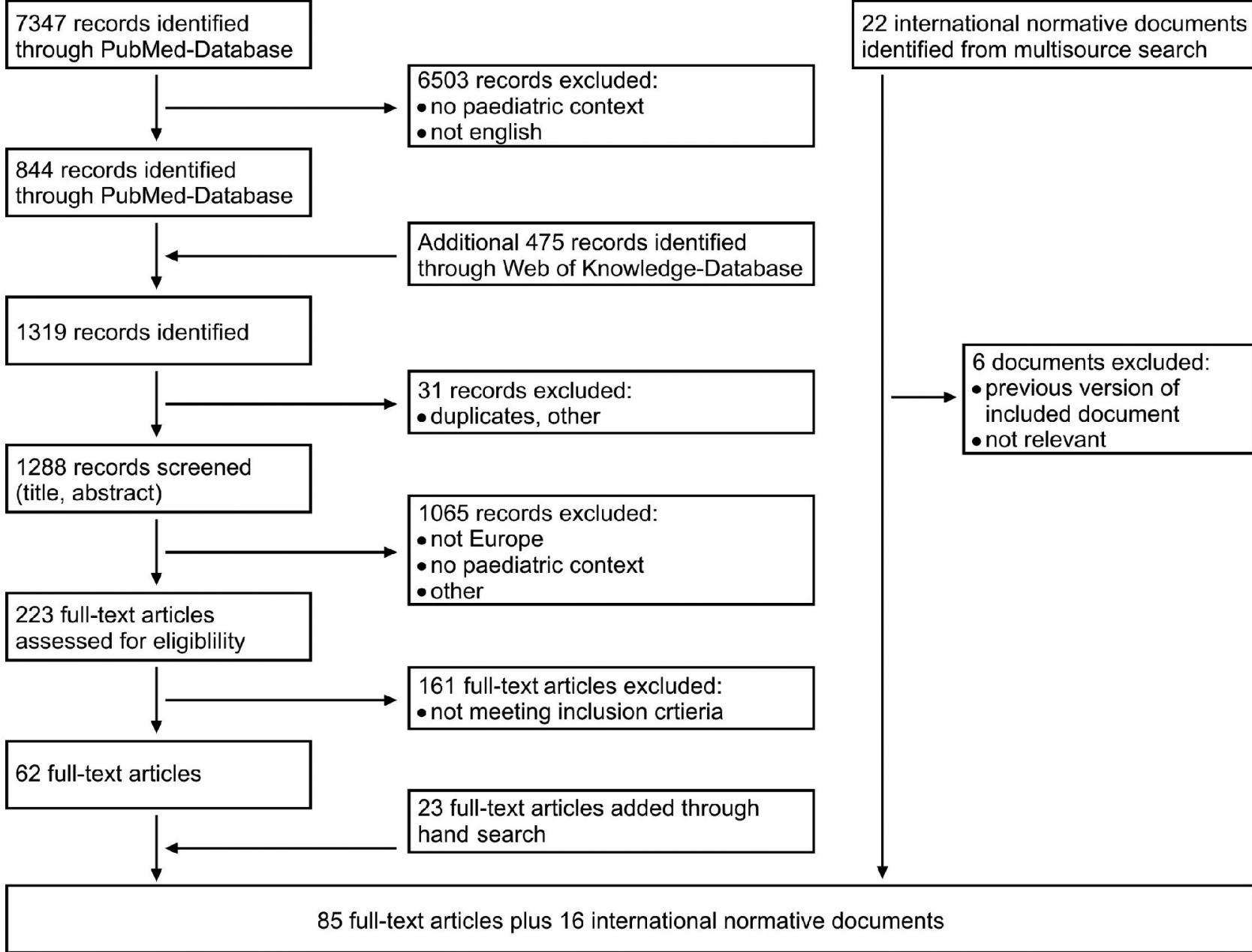

Figure 2 Literature selection flow chart. The search included the following MESH terms: data collection, ethics, biological specimen banks, confidentiality, informed consent by minors, specimen handling, quality improvement and jurisprudence. In addition, the following subheadings were used: legislation, classification, methods, organisation, administration, standards and instrumentation. The search was limited to literature relevant to the paediatric age group ( 0 to 18 years of age) and to Europe.

8 and 9), consent in paediatric research (recommendations 10-14), paediatric data- and biobanks: operational principles (recommendations 15 and 16), sharing of data and samples (recommendation 17-19) and commercialisation and third party access (recommendations 20 and 21). Face-to-face discussion further refined all recommendations resulting in an agreement of $>80 \%$ for all at the final consensus conference.

\section{Recommendations}

Guiding principles

The 2006 European Regulation No 1901/2006 of the European Parliament and of the Council on Medicinal Products for Paediatric Use (Paediatric Regulation) for the first time mandated the development and submission of an investigation plan for children at early stages of drug development in Europe. ${ }^{17}$ The regulation emphasised the specific needs of children and aimed to end their status as 'therapeutic orphans'. ${ }^{17}{ }^{18}$ In 2009, the EU Council published an action plan for rare diseases strongly encouraging Europe-wide collaborative studies including establishing sustainable infrastructure such as registries and biobanks. ${ }^{2}$ The plan mandated support for research training and sharing of tools and expertise across Europe. It emphasised the need for the development of European guidelines and recommendations for evaluation and treatment of rare diseases. ${ }^{2}$ The seventh Framework
Programme of the EU for Research 1982/2006/EC, Technological Development and Demonstration Activities encouraged the investigator-driven development of collaborative research networks, further building of European research capacity, and sharing of data and specimens. ${ }^{19}$ In 2013, the Biobanks and Biomolecular Resources European Research Infrastructure Consortium (BBMRI-ERIC) was charged with the development of the Europe-wide research infrastructure of biobanks. ${ }^{3}$ These general principles for collaborative paediatric research in Europe are captured in recommendations 1-3 (table 1).

\section{Ethics}

The 2008 International Ethical Guidelines for Epidemiological Studies prepared by the Council for International Organizations of Medical Sciences (CIOMS) and the WHO defined that all proposals to conduct research in human subjects must be submitted for review of scientific merit and ethical acceptability to review committees. It specified that ethics committees should establish working rules regarding frequency of meetings, a quorum of members, decision-making procedures and review of decisions. The guidelines specified that the committee should provide its rules to prospective investigators. ${ }^{20}$ In 2014 , the Regulation 536/2014 of the European Parliament and of the Council on Clinical Trials on Medicinal Products for Human 


\section{Box Search strategy}

(((()(('Data Collection/ethics'[Mesh] OR ‘Data Collection/ legislation and jurisprudence'[Mesh]))) OR (((((('Ethics/ classification'[Mesh] OR 'Ethics/ethics'[Mesh] OR 'Ethics/ legislation and jurisprudence'[Mesh] OR 'Ethics/methods'[Mesh] OR 'Ethics/organization and administration'[Mesh] OR 'Ethics/standards'[Mesh]))) OR ethics)) AND (('Biological Specimen Banks/classification'[Mesh] OR 'Biological Specimen Banks/ethics'[Mesh] OR 'Biological Specimen Banks/ instrumentation'[Mesh] OR 'Biological Specimen Banks/ legislation and jurisprudence'[Mesh] OR 'Biological Specimen Banks/methods'[Mesh] OR 'Biological Specimen Banks/ organization and administration'[Mesh] OR 'Biological Specimen Banks/standards'[Mesh])))) OR (((('Confidentiality/ethics'[Mesh] OR 'Confidentiality/legislation and jurisprudence'[Mesh] OR 'Confidentiality/organization and administration'[Mesh] OR 'Confidentiality/standards'[Mesh]))) AND (('Biological Specimen Banks/classification'[Mesh] OR 'Biological Specimen Banks/ethics'[Mesh] OR 'Biological Specimen Banks/ instrumentation'[Mesh] OR 'Biological Specimen Banks/ legislation and jurisprudence'[Mesh] OR 'Biological Specimen Banks/methods'(Mesh) OR 'Biological Specimen Banks/ organization and administration'[Mesh] OR 'Biological Specimen Banks/standards'[Mesh])))) OR (('Informed Consent By Minors/ethics'[Mesh] OR 'Informed Consent By Minors/ legislation and jurisprudence'[Mesh] OR 'Informed Consent By Minors/organization and administration'[Mesh] OR 'Informed Consent By Minors/standards'[Mesh]))) OR ((((()('Specimen Handling/ethics'[Mesh] OR 'Specimen Handling/legislation and jurisprudence'[Mesh]))) OR (('Specimen Handling/ standards'[Majr]) AND 'Quality Improvement'[Mesh])) OR (('Specimen Handling'[Mesh]) AND 'Ethics'[Mesh])) OR (('Jurisprudence'[Majr]) AND 'Specimen Handling'[Majr])) OR (((('Specimen Handling'[Majr]) And ('legislation and jurisprudence' [Subheading]))) OR (('Specimen Handling'[Majr]) AND 'ethics' [Subheading]))))) OR (('Data Collection/ ethics'[Majr:NoExp] OR 'Data Collection/legislation and jurisprudence'[Majr:NoExp]))

Use (Clinical Trials Regulation) aimed to simplify and harmonise the administrative provisions of clinical trials in Europe. ${ }^{21}$ It mandated the submission of a single application dossier to all the member states concerned through a single submission portal. The regulation defined that member states were to determine the appropriate body to be involved in the assessment of the application and to organise the involvement of ethics committees within a specific timeline of the trial. It further specified that the designated ethics committee had to have appropriate expertise and membership to review the application. ${ }^{21}$ Concepts of centralisation, transparency and organisational expertise of ethics committees are captured in recommendations 4-7 (table 1).

\section{Paediatric principles}

The 1989 Convention on the Rights of the Child defined principles founded on respect for the dignity and worth of each child, regardless of race, colour, gender, language, religion, opinions, origins, wealth, birth status or ability. ${ }^{12}$ The convention aimed to protect children, to help secure their basic needs and to enhance the possibility of reaching their best potential. ${ }^{12} 22$ The World Medical Association statement of the Declaration of Helsinki of Ethical Principles for Medical Research Involving Human
Subjects emphasised the importance of special protection of vulnerable populations including children. ${ }^{23}$ It specified that medical research with a vulnerable group such as children is only justified, if the research is responsive to the health needs and priorities and cannot be carried out in a non-vulnerable group. ${ }^{23}$ The benefit of participating in a research study has to outweigh the potential risk. ${ }^{21}$ The principle of minimal risk is a virtual standard for research in children. ${ }^{24}$ Minimal risk is considered a risk that is similar to the child's risk in everyday life ${ }^{22}$ and should not be greater than the risk attached to a routine medical examination. $^{25}$ The 2014 Clinical Trials Regulation specified that research in children should be performed out of necessity and a presumed benefit for the minor directly or for children with the same condition. ${ }^{2124}$ The principles of subsidiarity and the paediatric rule are captured in the recommendations 8 and 9 (table 1).

\section{Consent in paediatric research}

The 2008 CIOMS/WHO International Ethical Guidelines for Epidemiological Studies mandated that before undertaking research involving children the investigator must ensure that a parent or legal representative of each child has given permission. In addition, the agreement of each child (assent) has to be obtained to the extent of the child's capability. ${ }^{20}$ It demands that the investigator must convey the information in language suitable to the individual child's level of understanding and abilities. The consent/assent process has to include provision of sufficient time and opportunities for clarification. ${ }^{20}$ The 2009 Organisation for Economic Co-Operation and Development (OECD) Guidelines on Human Biobanks and Genetic Research Databases suggested participants should be given a range of possible scopes of consent to choose from including broad consent to minimise potential risk of harm. In addition, the participant's right to withdraw from the research at any time has to be emphasised. ${ }^{26}$ The 2016 Recommendation CM/Rec (2016)6 of the Committee of Ministers to Member States on Research on Biological Materials of Human Origin defined that re-consent has to be obtained, when a person attains capacity to consent. ${ }^{27}$ It also mandated that clear policies should be in place ensuring communication of concerning findings that are relevant for the health of the persons-the so-called incidental findings. ${ }^{27}$ While in adults based on the Unesco International Declaration on Human Genetic Data the right of an individual to decide whether or not to be informed of the results of genetic examinations should be respected, ${ }^{28}$ the importance to act in the best interest of minors may override this right in children. ${ }^{29}$ Refusal to be informed about clinically relevant findings therefore represents a barrier for the participation of minors in research; parents cannot make the choice for their children not to be informed about clinically relevant research. ${ }^{29}$ The concepts of consent/assent, withdrawal of consent, re-consenting and incidental findings in paediatric research are captured in the recommendations 10-14 (table 1).

\section{Paediatric data- and biobanks}

The 2009 OECD Guidelines on Human Biobanks and Genetic Research Databases mandated that data- and biobanks should be governed by principles of transparency and accountability including a clear formulation of governance structure and responsibility for its management. ${ }^{26}$ It also demanded that operators should have protocols and processes in place to protect participants' personal and medical information. The 2013 European Commission Implementing Decision of the BBMRI-ERIC was charged with establishing and operating a pan-European research infrastructure including improved interoperability of 
Table 1 Recommendations for collaborative paediatric research including biobanking in Europe

\begin{tabular}{l}
\hline Text of recommendations \\
\hline Guiding principles \\
Recommendation 1: Advancing care and discovery \\
Research in children should be supported including international, \\
multicentre data collection and banking and transfer of biological \\
specimens. Collaboration enables discovery in paediatric diseases \\
and care advancement for children, in particular for those with rare \\
diseases.
\end{tabular}

\section{Recommendation 2: Enabling support}

Paediatric researchers should be offered research training opportunities, access to mentorship and guidance, protected time and financial support to conduct paediatric research. Institutional resources for research protocol development, translation services, ethics submission and research conduct should be made available.

\section{Recommendation 3: Supportive legislative framework} A supportive legislative framework for international collaborating biobanks is lacking. A framework (WHO, ICH, EMA, FDA, other) should be implemented to overcome legal and ethical barriers in international research. An international binding shipment and custom agreement for biological samples should be established.

\section{Ethics}

\section{Recommendation 4: Centralised ethics}

All international collaborative paediatric research should be reviewed by central European Ethics Committees. All auxiliary studies require additional review and approval. The review has to capture all ethical principles including privacy rights.

\section{Recommendation 5: Standardisation and transparency}

All collaborative paediatric research applications in the European Community should be filed in a standardised format and be submitted to a central electronic application portal. Following submission, the review process should be transparent and electronically traceable.

\section{Recommendation 6: Central competency}

The European Central Ethics Application Board should rapidly assess all multicentre applications for meeting formal EU standards. All applications including timelines should be tracked in a central repository. The application should be transferred to the applicant's designated National Ethics Committee for Paediatric Research and Biobanking and undergo review including compliance with the specific ethical principles. After signoff, the other participating National Ethics Committees should rapidly adopt the decision.

\section{Recommendation 7 (1): Membership expertise}

Each National Ethics Committee for Paediatric Research and Biobanking should operate according to uniform standards.

Membership: each committee has to include independent experts in paediatric research, lay members (non-professionals including patient/ parent organisations or community advocates) and those with specific content expertise including genetics to review specific applications when appropriate.

\section{Recommendation 7 (2): Support and clarity}

Ethics application: each committee should provide direct assistance, clear instructions and training courses to support the researcher. Instructions and applications should be written in a simple, universally understood language. Fees: administrative fees should exclusively be charged in non-academic research; if charged, they should not constitute an obstacle.

\section{Paediatric principles}

\section{Recommendation 8: Subsidiarity}

A study that will produce generalisable results across all age groups should preferentially be performed in adults.

\section{Recommendation 9: Paediatric rule}

Children should receive special protection when included in data and biobank studies.
Justification

Discovery and care advancement in paediatric diseases requires collaborative longitudinal research projects of international scale in order to include sufficient numbers of participants and generate robust scientific data. The international collaborative collection, storage and sharing of human biological material and associated clinical information reduce the overall burden of sampling for patients and researchers enabling sustained, high-quality research. ${ }^{217} 1822333535$

\section{The complexity of collaborative paediatric diseases research and the} heterogeneity of rules, regulations and processes within and across European countries mandate researchers to develop distinct skill sets and content knowledge. Focused, comprehensive training, institutional assistance and guidance partnered with financial and other support will enable researchers to overcome the disproportionally challenging barriers towards successful multinational paediatric diseases research requiring sample and data collection. $202836-38$

The regulatory requirements for paediatric biobanking vary significantly between European countries. This dramatically complicates the implementing of international paediatric diseases biobanks. A unified European framework should be developed and implemented in order to facilitate the international sharing of precious paediatric biospecimen and enable life-saving discoveries 32433 3739-42

Designated and highly qualified, independent and centralised ethics committees should serve as competent authority for paediatric research. Subsequent, auxiliary studies should be reviewed by the same committee. The resulting single ethics vote captures the highest ethical principles and privacy standards. Subsequently, National Ethics Committee reviews are solely tasked with evaluating cultural appropriateness. ${ }^{20} 212325-27334143$

The current necessity of multiple ethics applications, the large variability in the submitting formats and the lack of transparency of the reviewing process hinder collaborative paediatric research within the EU. A standardised submission and approval process through a central application portal as implemented in the EU portal for all clinical trials will overcome this barrier and facilitate research and care advancement. $^{21}$

The standardisation of application requirements and a unified primary, central review process overcomes barriers by simplifying the process while increasing the quality in accordance to the European regulation on clinical trials on medicinal products for human use (Clinical Trials Regulation). ${ }^{2144}$

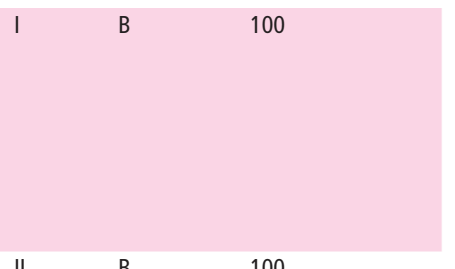

B

greement (\%)

egula studies and biobanking requires specific expertise reflected in its membership: paediatricians should provide advice on clinical, ethical and psychosocial aspects of research in minors. Lay members should offer support evaluating individual and societal impact of the proposed research. The review of genetic studies mandates an additional content expert for guidance. ${ }^{20212544-46}$

Administrative support, training opportunities and transparent, simple instructions will help facilitate the paediatric research ethics application. For investigator initiated, non-commercial studies fees y should not constitute a barrier to research. Fees should be set solely on the basis of cost recovery principles and be reduced or waived when appropriate. 20212847

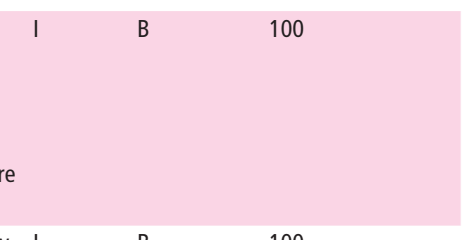

B $\quad 100$

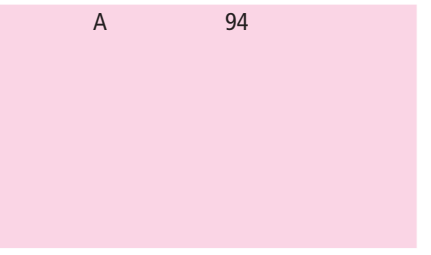

Adults should be primarily included in research studies; they are capable of giving truly informed consent. Children are a vulnerable population and need protection. Generalisable research has to be conducted in adults. 202223252733414244

Children are a vulnerable population. The potential risks including privacy risks related to genetic information, physical and emotional harms, and disrespect of values should be minimised during sample collection and the duration of the research study. Justification is required when inviting vulnerable individuals to serve as research subjects, the risk should be minimal and the means of protecting rights and welfare must be strictly applied. 20222325273342434548 
Table 1 Continued

Text of recommendations
Recommendation 10: Integration of minors
Voluntary and age-appropriate informed consent/assent has to be
obtained from legal guardians and/or minors as appropriate according
to the international guidelines (ICH, WHO, others) before paediatric
data and biospecimen can be collected and used for research. Minors
should be integrated into the process of consent and those capable
of forming an opinion and assessing the information given should be
asked to give assent or consent, as appropriate.

Recommendation 11: Enabling informed consent

All information given to the child and the legal guardian should be age appropriate, written and presented by a competent person in the country's official language. Paediatric participants and legal guardians should be granted appropriate time to make and reconsider their decision. Withdrawal of consent should be possible at any time of the study.

\section{Recommendation 12: Scope of consent}

The scope of consent should preferably be broad. Broad consent should include future research opportunities, possibility to share Broad consent should include the possibility to re-contact participants. Consent forms need to be internationally harmonised to ensure possibility for specimen shipment and data transfer. Consenting shou include the opportunity to opt out of certain aspects of research.

\section{Recommendation 13: Re-consenting}

Paediatric participants that have previously only given assent should be re-contacted for consent to an ongoing study when reaching legal age. Researchers should make considerable effort to re-contact participants for further use of data and samples. The ethics committe should evaluate the option of further use of data and sample, if participants are not reachable.

\section{Recommendation 14: Incidental findings}

Researchers should partner with expert healthcare providers and inform patients and legal guardians about clinically relevant results. Participant's refusal to be informed about clinically relevant results represents an exclusion criterion. samples and data with national and/or international research partners. international research projects. Consent forms have to include the

\section{Justification}

Children have the right to be included in research and benefit from research discoveries. All research mandates voluntary, informed consent given by a competent individual, who has received the necessary information and has adequately understood the information. The decision to participate has to be reached without coercion, undue influence or intimidation. Informed consent embodies the individual's freedom of choice and respects the individual's autonomy. Legal guardians may serve as proxies for minors, who do not have full capacity, in the consent process; children should be integrated in the consent process and their opinion and views have to be respected. $1220222325-273133434649-53$

The process of consenting must not be simply a ritual recitation of the contents of a written document. The information must be conveyed in language that suits the individual's level of understanding. Parents/ legal guardians and children must be given time and opportunity for discussion to make the decision without any pressure to

consent. Participants should be informed that consent/assent can be withdrawn at any time. Exercising the right to withdraw cannot entail consequences in medical care services. ${ }^{2022} 2325-27434648495254$

Broad consent reduces the burden for participants as it avoids the need for re-sampling of biospecimen and re-collection of data in addition to the need for re-consenting. Broad consent avoids the need to re-contact and re-consent participants, which may represent a significant barrier to conducting research. It allows for novel research to be conducted that had not been conceptualised at the time of the initial study. Permission for data and specimen transfer should be d included in the harmonised consent forms. A governance specification and an opt-out option have to be included enabling participants to limit the use of their specimens and data to distinct research questions. $^{22} 2627303743454855-57$

At time of reaching legal age, the formal legal status of the participant changes. This mandates obtaining re-consent since the initial consent was not obtained from the minor and therefore has limited temporal scope. Allowing the competent child a right to withdraw materials given into the biobank by proxy consent is consistent with the idea of a child's 'right to an open future', which states that choices made for a child when being a minor should not preclude the right to make decisions when reaching legal age. The former minor has now full autonomy and is now able to oversee the dimension of the research and can give informed consent for ongoing research generated from databases and biobanks. In case the participant cannot be reached, the researcher should seek advice from the ethics committee for further use of data and samples. ${ }^{1821} 222627485859$

In adults, the principle of autonomy and the individual right 'to know or not to know' defines the extent to which researchers should inform participants including children and their legal guardians about clinically relevant results detected in research studies. In paediatric studies, the proxy consent does not cover this decision. Here, researchers have a moral duty to inform minor participants and their legal guardians about clinically relevant results that mandate action including research result and incidental findings. Findings should be communicated by an expert clinician. ${ }^{2022} 232527-2933424360$

Paediatric data and biobanks: operational principles

Recommendation 15: Organisational framework

The organisational frameworks for collaborative paediatric data- and biobanks must include a governance structure. Terms of transparency, fair access to data and samples including ownership, authorship of research publications, payment and reciprocity of sample sharing should be defined. Principles of interoperability should be followed. Data and/or material transfer agreements should be elaborated and signed between research partners. Researchers should develop a longterm plan for sustainability. Biobanks should be captured in a central electronic tracking system.

\section{Recommendation 16: Sampling}

Non-invasive sampling approaches should be preferentially used in children. Standard operating procedures (SOPs) of paediatric sample collection, processing, pre-analytic handling and shipment should be defined and observed to ensure high-quality specimen handling.
An organisational framework prevents ethical and legal conflicts, and enables long-term collaborations between participating researchers. The development and endorsement of standards enables higher research interoperability. Transparency of the framework and its policies is necessary for biobanks in all levels. Standardised design and harmonisation of data fields enables interoperability between biobanks. A governance structure and a long-term sustainability plan will ensure public trust and long benefits. A central registry for European biobanks will not only reduce the burden of repeated sample collection but also helps to use existing resources in the most efficient way. ${ }^{321} 26-283337435761$

The Paediatric Rule mandates minimal invasive sampling, which may result in small quantities of biospecimen and may require designated, harmonised SOPs. Processing of paediatric biospecimen and capture of paediatric data samples should include necessary measures to ensure the accuracy, reliability, quality and security. ${ }^{20} 2527284146576162$

\begin{tabular}{lll} 
Level & Strength & Agreement (\%) \\
\hline I & A & 100 \\
& & \\
& \\
& \\
\end{tabular}

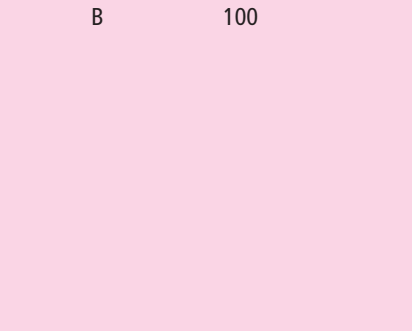

A

88

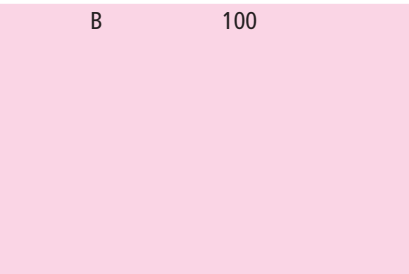

B

100

Continued 
Table 1 Continued

\begin{tabular}{ll}
\hline Text of recommendations & Justification \\
\hline $\begin{array}{l}\text { Recommendation 17: Data harmonisation } \\
\text { Collaborative databanks should build on available instruments of data }\end{array}$ & $\begin{array}{l}\text { Harmonisation of data fosters the interoperability of systems and } \\
\text { facilitates the exchange of scientific data. High-quality standards } \\
\text { harmonisation, standardised access to data, define measures of high } \\
\text { enable the possibility of international collaborative research with } \\
\text { health-related benefits for future generations. Quality assurance }\end{array}$ \\
& $\begin{array}{l}\text { measures should be implemented, including conditions to ensure } \\
\text { appropriate security and confidentiality during establishment of the } \\
\text { collection, storage, use and, where appropriate, transfer of data and } \\
\text { materials. }\end{array}$
\end{tabular}

Recommendation 18: Data protection

Researchers should implement a state-of-the-art data and sample protection system. Secure coding of data and samples should ensure confidentiality while enabling withdrawal of consent, re-consenting and notification of clinically relevant results. Secure data-sample linkage systems should be established.

Recommendation 19: Standardisation of transfer Specimen transfer should include standardised packaging and labelling, accompanying transfer documentation, customs regulations and sample tracking. The consent form must include the agreement to share data and samples.

Commercialisation and third party access

Recommendation 20: Fees and incentives

Biobanks should enable research to improve medical knowledge.

Provision of data and samples should be free; shipment and processing costs should be covered by the requesting research team. Participants or their parents should not receive payment. are responsible for establishing a system of secure safeguards for privacy, confidentiality and legitimate access. While using anonymous data and samples is the best way to protect personal information, it is not feasible in paediatric research as it limits the researchers' ability to act on withdrawal of consent, the need for re-consenting and the detection and notification of clinically relevant results. All data handling has to follow the standards of the EU General Data Protection Regulation. 20262730333746576163

Standardisation of shipment in accordance with international regulations and laws including all accompanying documents ensures a safe and confidential transfer of biological materials across borders. A documented agreement between the sender of the biological materials and the recipient should be signed. The patient's agreement of data and specimen transfer has to be obtained and shared. ${ }^{26-2835} 37$

Responsible sharing of biospecimen and data should be guided by the I principle of the 'Universal Declaration of Human Rights, 1948', which grants every individual the right to 'share in scientific advancement and its benefits'. In fact, the Council of Europe states that sharing of all knowledge and distribution of materials will be obligatory. Collaborative paediatric research aims to maximise discoveries by sharing of resources, data and samples. Financial incentives should be avoided. The operators of data and biobanks must ensure that any stratified access or fee policies are fair, transparent and do not inhibit research. 20252628333739616465

\section{Recommendation 21: Third parties}

Researchers have to obtain ethics approval before giving patient data or sample access to third parties. Continuous education of the public about biobanks is important to retain public trust in research.

The autonomy principle mandates that a patient has to give consent to any sharing of data and biospecimen. A researcher therefore should not share any data or specimens with third parties unless the patient permits such submission and an ethics approval was obtained. The most important prerequisite for successful biobank-related research is ensuring the public trust. This can be achieved through continuous education of people and protection of privacy. ${ }^{182025263033394345}$

EMA, European Medicines Agency; ICH, International Council for Harmonisation of Technical Requirements for Pharmaceuticals for Human Use.

data- and biobanks. ${ }^{3}$ It also mandated the implementation of quality management including standardised procedures and best practices. The 2016 Recommendation CM/Rec (2016)6 of the Committee of Ministers to Member States on Research on Biological Materials of Human Origin demanded safeguards to be put in place to ensure confidentiality at the time of collection, storage and transfer of biological materials. ${ }^{27}$ The 2016 Regulation 2016/679 of the European Parliament and the Council, the General Data Protection Regulation, mandated special protection of information originating from children. ${ }^{30}$ The concepts of organisation and conduct of paediatric data- and biobanks are captured in the recommendations 15-21 (table 1).

\section{DISCUSSION}

The SHARE initiative developed the first European recommendations for collaborative, paediatric research including biobanking for children with rheumatic diseases. A comprehensive systematic literature review including European legislative documents and an iterative consensus procedure was completed. A total of 21 recommendations were developed, refined and agreed on by expert clinicians in childhood disease, methodologists, paediatric researchers, and content experts of paediatric ethics and legislation, partnered with patient representatives. These recommendations will provide a robust framework for collaborative European research in rare childhood diseases in multicentre studies and the European Reference Networks that are currently being created.

Transformative European research in childhood diseases increasingly requires Europe-wide collaborations. This is particularly important for rare diseases such as the entire spectrum of rheumatic diseases of childhood. The proposed framework of recommendations includes concepts of guidance and support for collaborative research teams. It advocates increasing the competency and transparency of a proposed centralised ethics committee review processes of childhood rare diseases, as successfully modelled by the 2014 European Regulation on Clinical Trials. ${ }^{21}$ It provides evidence-based, structured guidance for all aspects of consent, data harmonisation, and standardisation of biospecimen standard operating procedures across Europe. This framework is the first of its kind. It was built on a comprehensive review of published evidence, guidance of European leaders in ethics and law, and practical experience of leading paediatric researchers and expert clinicians. Normative documents including ratified European laws and international declarations were reviewed and served as high-level evidence, an approach common to the area of ethics research, yet unfamiliar to medical researchers. Most importantly, the process has integrated the perspective of families living with childhood rare diseases. While being constructed in the context of the European Union funded research grant for paediatric rheumatic diseases, it 
is thought that it is likely to be transferrable to all collaborative childhood rare diseases research.

Research in children poses unique challenges and requires the inclusion of specific considerations. Most importantly, children have the right of designated paediatric research to advance the understanding of childhood diseases and development of best therapies. ${ }^{31}$ This right has to be balanced with the societal mandate to protect children from harm. ${ }^{12}$ The recommendations aim to strike this balance by including principles such as subsidiarity, the paediatric rule, the protection of minors and the minimisation of burden. ${ }^{22}$ Special considerations were given to the integration of minors in the consenting process. ${ }^{32}$ While consent is obtained from the legal guardian, minors have to be appropriately informed and have to have a voice in the decision-making process. ${ }^{33}$ It was emphasised that consent in paediatric research should be broad to minimise harm and that re-consenting is mandatory when minors reach legal age. ${ }^{27}$ The possibility of clinically relevant, actionable incidental findings has to be taken into account. ${ }^{34}$ Distinctly different from research in adults, refusal to be informed about these findings has to be considered an exclusion criterion for paediatric research study participation. $^{29}$

There are several limitations to the study and its results. The key limitation is the generalisability beyond Europe. Published literature and normative documents applicable to the European context only informed the recommendation development. The transferability into another cultural context such as North or South America has to be explored. When aiming so, the literature search and evidence synthesis would have to include publications and most importantly normative documents beyond Europe. In addition, the expert team had a content and method focus on childhood rheumatic diseases. In order to increase the generalisability care researchers, patients and families with a spectrum of other conditions including common and rare, acute and chronic illnesses would need to be part of the process. The transferability to other childhood diseases could then be tested; recommendations may require additional specifications when applied to a different disease context. However, it appears that principles captured in the proposed set of recommendations are widely generalisable across childhood diseases.

The SHARE initiative enabled the development of the first recommendations for Paediatric Rheumatology collaborative research including data- and biobanking and sharing across borders. These recommendations provide strong support for an urgently needed European legislative framework and evidencebased guidance for its implementation. Children with rheumatic conditions and the many others suffering from rare diseases should no longer be left behind when life-changing research discoveries can be made.

\footnotetext{
Author affiliations

'Division of Rheumatology, Department of Pediatrics, University Hospital Tuebingen, Tübingen, Germany

${ }^{2}$ Paediatric Rheumatology, Wilhelmina Children's Hospital, University Medical Center, Utrecht, The Netherlands

${ }^{3}$ Paediatric Rheumatology, Wilhelmina Children's Hospital, University Medical Center, Utrecht, The Netherlands

${ }^{4}$ Department of Philosophy, University of Antwerp, Antwerp, Belgium

${ }^{5}$ Pediatric Rheumatology, Hospital Sant Joan de Déu, Barcelona, Spain

${ }^{6}$ Departments of Allergy, Rheumatology and Clinical Immunology, University

Children's Hospital, University Medical Centre Ljubljana, Ljubljana, Slovenia

${ }^{7}$ Department of Paediatrics, University of Genoa, Gaslini Children's Hospital, G. Gaslini Research Institute, Genoa, Italy

${ }^{8}$ Department of Paediatric Rheumatology and Haematology, CEREMAI, GHU ParisSud - Hôpital de Bicêtre,APHP, Le Kremlin-Bicêtre, France

${ }^{9}$ Pediatric Rheumatology Unit, Department of Pediatrics, Meir Medical Center, KfarSaba, Kfar Saba, Israel
}

${ }^{10}$ Sackler Faculty of Medicine, Tel-Aviv University, Tel Aviv, Israel

${ }^{11}$ Department of Microbiology and Immunology, Laboratory Paediatric Immunology, UZ Leuven Hospital, Leuven, Belgium

${ }^{12}$ Department of Health, Ethics and Society, CAPHRI Research Institute, Maastricht

University, Maastricht, The Netherlands

${ }^{13}$ Institute for Biomedical Ethics, University of Basel, Basel, Switzerland

${ }^{14}$ Department of Pediatrics, Hacettepe University, Ankara, Turkey

${ }^{15}$ Paediatric Rheumatology, Wilhelmina Children's Hospital, University Medical Center, Utrecht, The Netherlands

${ }^{16}$ Department of General Pediatrics, Asklepios Clinic Sankt Augustin, Sankt Augustin, Germany

${ }^{17}$ Reumatológia, Immunológia, Gyermekgyógyászati Klinika, Budapest, Hungary

${ }^{18}$ Department of Paediatric Rheumatology, Institute for Translational Medicine, University of Liverpool, Alder Hey Children's NHS Foundation Trust, Liverpool, UK

${ }^{19} \mathrm{JIA}$ Patient Council, Department of Paediatric Rheumatology, University Medical

Center Utrecht, Wilhelmina Children's Hospital, Utrecht, The Netherlands

${ }^{20}$ Department of Paediatric Rheumatology, Great North Children's Hospital, Institute of Cellular Medicine Musculoskeletal Research Group, Newcastle University,

Newcastle upon Tyne, UK

${ }^{21}$ Alberta Children's Hospital Research Institute, Calgary, Alberta, Canada

Contributors All authors made substantial contributions to the conception or design of the work, or the acquisition, analysis or interpretation of data. All authors were involved in drafting the work or revising it critically for important intellectual content. There was final approval of the version published by all authors. All authors gave agreement to be accountable for all aspects of the work in ensuring that questions related to the accuracy or integrity of any part of the work are appropriately investigated and resolved.

Funding SHARE was funded by the European Agency for Health and Consumers (EAHC), No. 20111202

Competing interests None declared.

Provenance and peer review Not commissioned; externally peer reviewed.

(c) Article author(s) (or their employer(s) unless otherwise stated in the text of the article) 2017. All rights reserved. No commercial use is permitted unless otherwise expressly granted.

\section{REFERENCES}

1 EC. Programme of community action on rare diseases (1999 - 2003) decision no 1295/99/EC of the European Parliament and of the Council of 29 April 1999. 1999

2 EU. Council recommendation of 8 June 2009 on an action in the field of rare diseases (2009/C 151/02, 2009.

3 EU. Commission implementing decision on setting up the Biobanks and Biomolecular Resources Research Infrastructure Consortium (BBMRI-ERIC) as a European Research Infrastructure Consortium, 2013.

4 Wulffraat NM, Vastert B. SHARE consortium. Time to share. Pediatr Rheumatol Online J 2013;11:5.

5 Groot N, Graeff N, Avcin T, et al. European evidence-based recommendations for diagnosis and treatment of childhood-onset systemic lupus erythematosus: the SHARE initiative. Ann Rheum Dis 2017 (Epub ahead of print).

6 ter Haar NM, Oswald M, Jeyaratnam J, et al. Recommendations for the management of autoinflammatory diseases. Ann Rheum Dis 2015;74:1636-44.

7 Enders FB, Bader-Meunier B, Baildam E, et al. Consensus-based recommendations for the management of juvenile dermatomyositis. Ann Rheum Dis 2017;76:329-40.

8 Groot N, de Graeff N, Avcin T, et al. European evidence-based recommendations for diagnosis and treatment of paediatric antiphospholipid syndrome: the SHARE initiative. Ann Rheum Dis 2017.

9 Kranendonk EJ, Ploem MC, Hennekam RC. Regulating biobanking with children's tissue: a legal analysis and the experts' view. Eur J Hum Genet 2016;24:30-6.

10 Moher D, Liberati A, Tetzlaff J, et al. Preferred reporting items for systematic reviews and meta-analyses: the PRISMA statement. Int J Surg 2010;8:336-41.

11 Hutton B, Salanti G, Caldwell DM, et al. The PRISMA extension statement for reporting of systematic reviews incorporating network meta-analyses of health care interventions: checklist and explanations. Ann Intern Med 2015;162:777-84.

12 UN. Convention on the rights of the child. In: General Assembly resolution 44/25. United Nations, 1989

13 Dougados M, Betteridge N, Burmester GR, et al. EULAR standardised operating procedures for the elaboration, evaluation, dissemination, and implementation of recommendations endorsed by the EULAR standing committees. Ann Rheum Dis 2004;63:1172-6.

14 van der Heijde D, Aletaha D, Carmona L, et al. 2014 Update of the EULAR standardised operating procedures for EULAR-endorsed recommendations. Ann Rheum Dis 2015;74:8-13.

15 CEBM. Oxford Centre for Evidence-based Medicine Levels of Evidence. 2009 http:// www.cebm.net/?0=1116 
16 Harvey N, Holmes CA. Nominal group technique: an effective method for obtaining group consensus. Int J Nurs Pract 2012;18:188-94.

17 EU. European regulation No 1901/2006 of the European parliament and of the council on medicinal products for paediatric use: The European Parliament and the Council of the European Union, 2006.

18 Hens K, Nys H, Cassiman JJ, et al. Genetic research on stored tissue samples from minors: a systematic review of the ethical literature. Am J Med Genet $A$ 2009;149A:2346-58.

19 EU. Decision no 1982/2006/EC of the European parliament and of the council concerning the seventh framework programme of the European Community for research, technological development and demonstration activities (2007-2013): The European Parliament And Of The Council, 2006.

20 CIOMS. International ethical guidelines on epidemiological studies, 2008.

21 EU. Regulation (EU) no 536/2014 of the European parliament and of the council on clinical trials on medicinal products for human use, and repealing Directive 2001/20/ EC, 2014.

22 Hens K, Van El CE, Borry P, et al. Developing a policy for paediatric biobanks: principles for good practice. Eur J Hum Genet 2013;21:2-7.

23 WMA. WMA declaration of Helsinki - ethical principles for medical research involving human subjects. 64th WMA general assembly. Fortaleza, Brazil: World Medical Association, 2013

24 Pinxten W, Dierickx K, Nys H. Ethical principles and legal requirements for pediatric research in the EU: an analysis of the European normative and legal framework surrounding pediatric clinical trials. Eur J Pediatr 2009;168:1225-34.

25 CIOMS. International ethical guidelines for biomedical research involving human subjects, 2002.

26 OECD. Recommendation on human bioanks and genetic research databases, 2009.

27 Europe Co. Recommendation CM/Rec (2016)6 on research on biological materials of human origin, 2016.

28 UNESCO. International declaration on human genetic data, 2003.

29 Hens K, Nys H, Cassiman JJ, et al. The return of individual research findings in paediatric genetic research. J Med Ethics 2011;37:179-83.

30 EU. Regulation (EU) 2016/679 of the European parliament and of the council on the protection of natural persons with regard to the processing of personal data and on the free movement of such data, and repealing Directive 95/46/EC (General Data Protection Regulation), 2016.

31 Salvaterra E, Giorda R, Bassi MT, et al. Pediatric biobanking: a pilot qualitative survey of practices, rules, and researcher opinions in ten European countries. Biopreserv Biobank 2012:10:29-36.

32 Giesbertz NA, Bredenoord AL, van Delden JJ. Consent procedures in pediatric biobanks. Eur J Hum Genet 2015;23:1129-34.

33 Budimir D, Polasek 0, Marusić A, et al. Ethical aspects of human biobanks: a systematic review. Croat Med J 2011;52:262-79.

34 Avard D, Sénécal K, Madadi P, et al. Pediatric research and the return of individual research results. J Law Med Ethics 2011;39:593-604.

35 Lochmuller H, Schneiderat P. Biobanking in rare disorders. In: DelaPaz MP, Groft SC, eds. Rare diseases epidemiology, 2010:105-13.

36 Jackson C, Dixon-Woods M, Tobin M, et al. Seeking consent to tissue banking: a survey of health professionals in childhood cancer. Eur J Cancer Care 2009;18:391-400.

37 Cambon-Thomsen A, Rial-Sebbag E, Knoppers BM. Trends in ethical and legal frameworks for the use of human biobanks. Eur Respir J 2007:30:373-82.

38 Hens K, Snoeck J, Nys H, et al. An exploratory survey of professionals on the use of stored tissue samples from minors for genetic research. Genet Mol Res 2010;9:973-80

39 Godard B, Schmidtke J, Cassiman JJ, et al. Data storage and DNA banking for biomedical research: informed consent, confidentiality, quality issues, ownership, return of benefits. A professional perspective. Eur J Hum Genet 2003;11(Suppl 2):S88-S122.
40 Eriksson S, Höglund AT, Helgesson G. Do ethical guidelines give guidance? a critical examination of eight ethics regulations. Camb Q Healthc Ethics 2008;17:15-29.

41 Hens K, Nys H, Cassiman JJ, et al. Biological sample collections from minors for genetic research: a systematic review of guidelines and position papers. Eur J Hum Genet 2009;17:979-90.

42 Hens K, Lévesque E, Dierickx K. Children and biobanks: a review of the ethical and legal discussion. Hum Genet 2011;130:403-13.

43 WHO. Genetic databases - assessing the benefits and the impact on human \& patient rights, 2003.

44 Pinxten W, Dierickx K, Nys H. The implementation of Directive 2001/20/EC into Belgian law and the specific provisions on pediatric research. Eur J Health Law 2008;15:153-61.

45 Hens K, Nys H, Cassiman JJ, et al. Risks, benefits, solidarity: a framework for the participation of children in genetic biobank research. J Pediatr 2011;158:842-8.

46 Merlo DF, Knudsen LE, Matusiewicz K, et al. Ethics in studies on children and environmental health. J Med Ethics 2007;33:408-13.

47 Mumford SE. Children of the 90s: ethical guidance for a longitudinal study. Arch Dis Child Fetal Neonatal Ed 1999;81:F146-51.

48 Hens K, Cassiman JJ, Nys H, et al. Children, biobanks and the scope of parental consent. Eur J Hum Genet 2011;19:735-9.

49 Holm SØren. Informed consent and the bio-banking of material from children. Genomics, Society and Policy 2005; 1 .

50 Hens K, Nys H, Cassiman JJ, et al. The storage and use of biological tissue samples from minors for research: a focus group study. Public Health Genomics 2011;14:68-76.

51 van der Pal S, Sozanska B, Madden D, et al. Opinions of children about participation in medical genetic research. Public Health Genomics 2011;14:271-8.

52 Waligora M, Dranseika V, Piasecki J. Child's assent in research: age threshold or personalisation? BMC Med Ethics 2014;15:44.

53 Giesbertz NA, Bredenoord AL, van Delden JJ. Clarifying assent in pediatric research. Eur J Hum Genet 2014;22:266-9.

54 Soto C, Tarrant C, Pritchard-Jones K, et al. Consent to tissue banking for research: qualitative study and recommendations. Arch Dis Child 2012;97:632-6.

55 Toccaceli V, Serino L, Stazi MA. Informed consent, and an ethico-legal framework for paediatric observational research and biobanking: the experience of an Italian birth cohort study. Cell Tissue Bank 2014;15:579-90.

56 Hansson MG. Ethics and biobanks. Br J Cancer 2009;100:8-12.

57 European Society of Human Genetics. Data storage and DNA banking for biomedical research: technical, social and ethical issues. Eur J Hum Genet 2003;11(Suppl 2):S8-10.

58 Helgesson G. Children, longitudinal studies, and informed consent. Med Health Care Philos 2005;8:307-13.

59 Feinberg J. "On the child's right to an open future," in whose child? Rowman \& Littlefield, 1980.

60 Anastasova V, Mahalatchimy A, Rial-Sebbag E, et al. Communication of results and disclosure of incidental findings in longitudinal paediatric research. Pediatr Allergy Immunol 2013;24:389-94.

61 Knoppers BM. Framework for responsible sharing of genomic and health-related data. Hugo J 2014;8:3.

62 Balaguer J, Cañete A, Costa E, et al. Tumour banks in pediatric oncology. Clin Trans/ Oncol 2006:8:884-8.

63 Mascalzoni D, Janssens AC, Stewart A, et al. Comparison of participant information and informed consent forms of five European studies in genetic isolated populations. Eur J Hum Genet 2010;18:296-302.

64 Merlo DF, Vahakangas K, Knudsen LE. Scientific integrity: critical issues in environmental health research. Environ Health 2008;7(Suppl 1):S9.

65 UN. Universal declaration of human rights: Assembly UNG, 1948. 

paediatric research including biobanking in Europe: a Single Hub and Access point for paediatric Rheumatology in Europe (SHARE) initiative

Jasmin B Kuemmerle-Deschner, Sandra Hansmann, Nico M Wulffraat, Sebastiaan J Vastert, Kristien Hens, Jordi Anton, Tadej Avcin, Alberto Martini, Isabelle Koné-Paut, Yosef Uziel, Angelo Ravelli, Carine Wouters, David Shaw, Seza Özen, Andreas Eikelberg, Berent J Prakken, Nicolino Ruperto, Gerd Horneff, Tamas Constantin, Michael W Beresford, Marijn Sikken, Helen E Foster, Iris Haug, Sabrina Schuller, Christine Jägle and Susanne M Benseler

Ann Rheum Dis published online October 11, 2017

Updated information and services can be found at:

http://ard.bmj.com/content/early/2017/10/11/annrheumdis-2017-2119 04

\section{These include:}

References This article cites 43 articles, 9 of which you can access for free at: http://ard.bmj.com/content/early/2017/10/11/annrheumdis-2017-2119 04\#BIBL

Email alerting Receive free email alerts when new articles cite this article. Sign up in the service box at the top right corner of the online article.

\section{Notes}

To request permissions go to:

http://group.bmj.com/group/rights-licensing/permissions

To order reprints go to:

http://journals.bmj.com/cgi/reprintform

To subscribe to BMJ go to:

http://group.bmj.com/subscribe/ 